\title{
Acupuncture- Mediated Activation of the Cholinergic Anti-Inflammatory Pathway- A Review of the Literature
}

\author{
Zogopoulos Panagiotis ${ }^{1 *}$, Karavis Miltiades ${ }^{2}$, Venetikidis Anastasios ${ }^{1}$, Vretakos Georgios ${ }^{1}$, Theocharis \\ Stamatios $^{3}$ and Rologis Dimitrios ${ }^{1}$ \\ ${ }^{1}$ Neurosurgery Department, Metropolitan Hospital, Greece \\ ${ }^{2}$ Acupuncture Department, Filoktitis Rehabilitation Center, Greece \\ ${ }^{3}$ First Department of Pathology, University of Athens, Greece
}

Submission: November 24, 2016; Published: January 10, 2017

*Corresponding author: Zogopoulos Panagiotis, Neurosurgery Department, Metropolitan Hospital, Athens, Greece,

Email: p.zogopoulos@yahoo.com

\section{Abstract}

Immune system plays a pivotal role in protecting the body from pathogens, as well as from various insults, and consequently in maintaining homeostasis. Acupuncture has been used for many centuries in Asia but also, over the last decades, in Western countries, as a treatment modality for various diseases and disorders. Recent advances have shed light on the mechanisms of action of acupuncture treatment and there is now evidence that it can activate the so called "cholinergic anti-inflammatory pathway", especially through modulation of the vagal tone. We present available experimental data, to date, regarding acupuncture's effects on the immune system through the cholinergic anti-inflammatory pathway.

\section{Introduction}

Human body has an embedded immune system that is responsible for its protection against invading pathogens or tissue injury [1]. Keeping a balance between pro-inflammatory responses (that mediate inflammation) and anti-inflammatory mechanisms (that prevent excessive inflammatory responses) is vital to maintain homeostasis [2,3]. Production and release of cytokines (proteins produced by immune cells) is a key element in mediating inflammation. Most known cytokines include tumor necrosis factor (TNF), interleukin (IL)-1, IL-6 and high mobility group B1 (HMGB1) [2,4]. On the other hand, a neural pathway referred to as the "cholinergic anti-inflammatory pathway" plays a major role in suppressing inflammation.

In most cases immune system manages to eliminate exogenous or endogenous threats and restore homeostasis. When this is not achieved, inflammatory responses can lead to an uncontrolled tissue damage. Specifically, overproduction of cytokines has been implicated in the pathogenesis of various diseases, including Crohn's disease, Alzheimer's disease, multiple sclerosis, diabetes and rheumatoid arthritis, but also in conditions such as endotoxemia and sepsis [5-8]. Recent evidence suggest that vagus nerve can regulate inflammatory responses through the cholinergic anti-inflammatory pathway, resulting in decreased TNF production and thus, in suppression of inflammation $[1,3,9,10]$. Acupuncture, an ancient treatment modality originating from China, is under extensive research over the last decades, regarding its mechanisms of action and recent experimental data suggest that it can mediate its effects through the cholinergic anti-inflammatory pathway.

\section{Experimental Data}

The vagus nerve has been shown to mediate immune function regulation by the central nervous system through a pathway called "cholinergic anti-inflammatory pathway" [11]. Vagus nerve fibers synapse at the celiac-superior mesenteric plexus ganglia and they modulate splenic nerve activity through the activation of nicotinic acetylcholine receptor [12]. Consequently, splenic nerve releases norepinephrine that acts on adrenergic receptors of $\mathrm{B}$ and $\mathrm{T}$ cells of the spleen, which in turn produce acetylcholine [13,14]. Finally, increased acetylcholine levels inhibit proinflammatory cytokine release by macrophages, acting on their nicotinic receptors [15].

Unilateral vagotomy in rats abolished the protective effects of electroacupuncture (EA) pretreatment in a lethal endotoxemia experimental model [16]. Moreover, systemic 


\section{Open Access Journal of Neurology \& Neurosurgery}

administration of mecamylamine (a nicotinic antagonist) also blocked the protective effects of EA, but atropine methyl nitrate (a muscarinic antagonist) systemic administration failed to block EA protection [16]. However, direct delivery of atropine methyl nitrate into the brain resulted in complete reversal of EA's protective effects. These results indicate that the central muscarinic receptors are important elements of the peripheral cytokine production pathway [16].

Severe burns or trauma patients often exhibitgastrointestinal ischemia and paralysis that can lead to dysfunction of the intestinal epithelial barrier and consequently to multiple organ failure [17]. Various experimental animal studies have shown that electrical stimulation of the vagus nerve might exert a protective anti-inflammatory effect on the intestinal barrier activity after burn injuries through activation of the cholinergic anti-inflammatory pathway $[18,19]$. However, electrical stimulation of vagus nerve in humans is rather complicated since it requires a surgical approach often associated with untoward side effects, such as serious tissue injury. Acupuncture at particular acupoints (such as ST36) has similar effects to those of vagus nerve activation $[18,19]$. Recent animal studies in rats after scald injury have shown that EA at ST36 acupoint significantly increased gastrointestinal mucosal blood flow, while plasma diamine oxidase (DAO) and intestinal permeability were significantly decreased compared with the control group [20-22]. However, these protective effects of EA were abolished after intraperitoneal atropine injection or vagotomy, suggesting that EA acts, at least in part, in the presence of intact vagus neurenteric innervation through the activation of the cholinergic nerve pathway [22].

It has been suggested that acupuncture-mediated activation of the cholinergic anti-inflammatory pathway involves acetylcholine release from vagus nerve that binds to $\alpha 7$-nicotinic receptors (a7-nAChRs) on macrophages and thus, inhibits the release of proinflammatory cytokines [10]. However, there are reports that vagal immuno-modulation by EA might also be mediated by dopamine release [19].

EA at bilateral ST36 acupoints has been shown to significantly decrease plasma concentration of TNF- $\alpha$, but did not affect IL-10 levels [23]. However, after bilateral cervical vagotomy EA at ST36 failed to decrease the concentration of TNF- $\alpha$, suggesting that EA acts through the activation of cholinergic anti-inflammatory pathway [23].

EA at ST36 acupoints induces a significant effect on central nuclei of the vagus nerve, such as the dorsal nuclei of vagus nerve, solitary tract, nucleus of solitary tract and ambiguous nucleus [24]. Neurons of cornu dorsale medullae spinalis could receive afferent somatic messages from ST36, which in turn are transmitted to the nucleus of solitary tract (the splanchnic sensory nucleus), thus affecting stomach motility and electrical release by efferent vagus nerve. EA at ST36 can also excite efferent vagus nerve fibers and increase the frequency and value of electrical discharge [25].

EA at PC- 6 acupoint significantly increases vagal activity, as measured by spectral analysis of heart rate variability $[26,27]$. EA at LI-4 acupoint has also been shown to increase vagal tone (vagus nerve activity) through somato-autonomic reflexes that activate brain muscarinic receptors [28,29]. However, there are reports that EA at LI-4 acupoint increases sympathetic tone, as indicated by blood pressure elevation and increased renal and adrenal nerve activities, which means that certain acupoints can have dual effects on both the sympathetic and parasympathetic systems $[30,31]$.

\section{Discussion}

Immune system plays a major role in maintaining homeostasis and acupuncture has been recently shown to regulate inflammatory responses through the activation of the cholinergic anti-inflammatory pathway. Understanding immune system innervation can provide modern medicine with new tools to prevent, as well as treat immune-mediated disorders and diseases such as rheumatoid arthritis, Crohn's disease, Alzheimer disease, multiple sclerosis etc. Recent advances in neuroradiology and immunohistochemistry have revealed new pathways and mechanisms of action of acupuncture treatment and have particularly shed light on its immunomodulatory effects. Activation of cholinergic anti-inflammatory pathway may be one of the most important mechanisms of EA-mediated anti-inflammation and organ protection.

\section{Conclusion}

Acupuncture and, especially its more potent form electroacupuncture, have been proved to exert anti-inflammatory actions, at least in part, through the activation of the so called cholinergic anti-inflammatory pathway. Therefore, acupuncture should be part of the armamentarium of each physician treating patients with immune-mediated disorders, since it could affect disease progression and thus, improve quality of life.

\section{References}

1. Tracey KJ, Czura CJ, Ivanova S (2001) Mind over immunity. FASEB J 15(9): 1575-1576.

2. Tracey KJ (2005) Fat meets the cholinergic anti-inflammatory pathway. J Exp Med 202(8): 1017-1021.

3. Oke SL, Tracey KJ (2009) The Inflammatory Reflex and the Role of Complementary and Alternative Medical Therapies. Ann N Y Acad Sci 1172: 172-180.

4. Nathan C (2002) Points of control in inflammation. Nature 420(6917): 846-852.

5. Tracey JK (2002) The inflammatory reflex. Nature 420(6917): 853859.

6. Popa C (2007) The role of TNF-alpha in chronic inflammatory conditions, intermediary metabolism, and cardiovascular risk. J Lipid Res 48(4): 751-762. 


\section{Open Access Journal of Neurology \& Neurosurgery}

7. Zogopoulos P, Vretakos G, Rologis D (2015) Therapeutic implications of the endocannabinoid system in neurodegenerative diseases. Clin Case Rep Rev 1(4): 74-80.

8. Zogopoulos P, Venetikidis A, Vretakos G, Rologis D (2016) Acupuncture Treatment for Multiple Sclerosis - Can It Be Effective? J J Pharma Pharmacovigilance 2(2): 013

9. Libert C (2003) Inflammation: A nervous connection. Nature 421(6921): 328-329.

10. Tracey KJ (2007) Physiology and immunology of the cholinergic antiinflammatory pathway. The Journal of Clinical Investigation 117(2): 289-296.

11. Tracey KJ (2009) Reflex control of immunity. Nat Rev Immunol 9(6): 418-428.

12. Vida G, Pena G, Deitch EA, Ulloa L (2011) $\alpha 7$-cholinergic receptor mediates vagal induction of splenic norepinephrine. J Immunol 186(7): 4340-4346.

13. Brandon KW, Rand MJ (1961) Acetylcholine and the sympathetic innervation of the spleen. J Physiol 157(1): 18-32.

14. Leaders FE, Dayrit C (1965) The cholinergic component in the sympathetic innervation to the spleen. J Pharmacol Exp Ther 147: 145-152.

15. Song JG, Li HH, Cao YF, Lv X, Zhang P, et al. (2012) Electroacupuncture Improves Survival in Rats with Lethal Endotoxemia via the Autonomic Nervous System. Anesthesiology. 116(2): 406-414.

16. Pavlov VA, Ochani M, Gallowitsch-Puerta M, Ochani K, Huston JM, et al. (2006) Central muscarinic cholinergic regulation of the systemic inflammatory response during endotoxemia. Proc Natl Acad Sci U S A 103(13): 5219-5223.

17. Ulloa L (2005) The vagus nerve and the nicotinic anti-inflammatory pathway. Nature Reviews Drug Discovery 4(8): 673-684.

18. Du MH, Luo HM, Hu S, Lv Y, Lin ZL, et al. (2013) Electroacupuncture improves gut barrier dysfunction in prolonged hemorrhagic shock rats through vagus anti-inflammatory mechanism. World J Gastroenterol 19(36): 5988-5999.

19. Torres-Rosas R, Yehia G, Peña G, Mishra P, del Rocio Thompson-Bonilla $\mathrm{M}$, et al. (2014) Dopamine mediates vagal modulation of the immune system by electroacupuncture. Nat Med 20(3): 291-295.

20. Huo ZJ, Zhang L, Qian RQ (2003) Effects of Electro acupuncture of Different Acupoint Groups on Blood TNF- $\alpha$, IL-6, WBC and Cerebral
Free Radicals in Cerebral Ischemia-Reperfusion Rats. Acupuncture Research 28: 94-98.

21. Suo XY, Du ZH, Wang HS, Li JG, Wang YL, et al. (2010) The effects of stimulation at acupoint ST36 points against hemorrhagic shock in dogs. Am J Emerg Med 29(9): 1188-1193.

22. Wang H, Wang L, Shi X, Qi S, Hu S, et al. (2015) Electroacupuncture at Zusanli Prevents Severe Scalds-Induced Gut Ischemia and Paralysis by Activating the Cholinergic Pathway. Evid Based Complement Alternat Med 787393: 1-6.

23. Song Q, Hu S, Wang H, Lv Y, Shi X, et al. (2014) Electroacupuncturing at Zusanli point (ST36) attenuates pro-inflammatory cytokine release and organ dysfunction by activating cholinergic anti-inflammatory pathway in rat with endotoxin challenge. Afr J Tradit Complement Altern Med 11(2): 469-474.

24. Liu JH, Yan J, Yi SX, Chang XR, Lin YP, et al. (2004) Effects of electroacupuncture on gastric myoelectric activity and substance $\mathrm{P}$ in the dorsal vagal complex of rats. Neurosci Lett 356(2): 99-102.

25. Ye XF, Li JG, Du ZH (2006) Effect of Electroacupuncture at "Zusanli"(ST 36) on Vagal Electrical Activity in the Rat. Acupuncture Res 31:290293.

26. Ouyang H, Yin J, Wang Z, Pasricha PJ, Chen JD (2002) Electroacupuncture accelerates gastric emptying in association with changes in vagal activity. Am J Gastrointest Liver Physiol 282(2): 390-396.

27. Huang ST, Chen GY, Lo HM, Lin JG, Lee YS, et al. (2005) Increase in the vagal modulation by acupuncture at neiguan point in the healthy subjects. Am J Chin Med 33(1): 157-164.

28. Budgell B, Sato A (1996) Modulations of autonomic functions by somatic nociceptive inputs. Prog Brain Res 113: 525-539.

29. Haker E, Egekvist H, Bjerring P (2000) Effect of sensory stimulation (acupuncture) on sympathetic and parasympathetic activities in healthy subjects. J Auton Nerv Syst 79(1): 52-59.

30. Lin TB, Fu TC, Chen CF, Lin YJ, Chien CT (1998) Low and high frequency electroacupuncture at Hoku elicits a distinct mechanism to activate sympathetic nervous system in anesthetized rats. Neurosci Lett 247(23): 155-158.

31. Lin TB, Fu TC (2000) Effect of electroacupuncture on blood pressure and adrenal nerve activity in anesthetized rats. Neurosci Lett 285(1): 37-40.

\section{Your next submission with Juniper Publishers} will reach you the below assets

- Quality Editorial service

- Swift Peer Review

- Reprints availability

- E-prints Service

- Manuscript Podcast for convenient understanding

- Global attainment for your research

- Manuscript accessibility in different formats

( Pdf, E-pub, Full Text, Audio)

- Unceasing customer service

Track the below URL for one-step submission https://juniperpublishers.com/submit-manuscript.php 